\title{
The Formation of Terminal Fields in the Absence of Competitive Interactions Among Primary Motoneurons in the Zebrafish
}

\author{
Dennis W. C. Liu ${ }^{\mathrm{a}}$ and Monte Westerfield \\ Institute of Neuroscience, University of Oregon, Eugene, Oregon 97403
}

To make specific synaptic connections, projection neurons extend neurites to regions contalning appropriate targets, then form synapses with the correct type and number of target cells. To investigate the mechanisms controlling this process, we have studied the formation of motoneuronal terminal fields in live zebrafish embryos. The primary motoneurons of the zebrafish are identifiable as individuals and innervate neighboring but mutually exclusive territories. To study the first week of their development, which includes embryonic and early larval stages, we labeled identified motoneurons with fluorescent dyes and made sequential observations of the axonal branches of individual neurons. We assessed the roles of competitive interactions and synapse elimination in the formation of specific synapses by identified neurons that innervate neighboring territories.

Our results demonstrate that primary motoneurons establish their cell-specific terminal fields primarily by directed outgrowth of branches and formation of neuromuscular junctions almost exclusively on appropriate muscle fibers, rather than by overproduction and selective elimination of inappropriate branches. Retraction of the few branches that are inappropriately placed, though correlated in time with the ingrowth of branches from appropriate motoneurons, occurs independently of the influences of these other cells and when neuromuscular transmission is blocked. We suggest that, similar to the way in which they pioneer peripheral nerve pathways, primary motoneurons establish their cell-specific terminal fields using mechanisms that operate independently of activity and competition. The target or substrate interactions that are likely to instruct directed growth-cone navigation may be similar to the interactions that determine the locations of territorial borders and that instruct the retraction of misplaced branches.

Pathfinding by the growth cones of pioneering peripheral axons has been studied extensively in a variety of insects (Bentley and Keshishian, 1982; Goodman et al., 1982; Blair and Palka, 1985). In cases in which the final specificity of synaptic connections is known, growth cones extend directly toward appropriate targets (Ball et al., 1985; Johansen et al., 1989; Myers et al., 1990).

Received May 8, 1990; revised Aug. 6, 1990; accepted Aug. 10, 1990.

This work was supported by NIH Grants NS21132, HD22486, and GM07257, the Murdoch Foundation, and an RCDA to M.W. We wish to acknowledge Harrison Howard and Sean. Poston for expert photographic assistance and Judith Eisen, Charles Kimmel, and Janis Weeks for comments on the manuscript.

Correspondence should be addressed to Monte Westerfield at the above address.

${ }^{a}$ Present address: Department of Genetics, University of Washington, Seattle, WA 98195.

Copyright (C) 1990 Society for Neuroscience $0270-6474 / 90 / 123947-13 \$ 03.00 / 0$
Evidence from studies of several vertebrate species suggests that the growth cones of spinal motoneurons grow directly to the regions of their appropriate targets, and, if displaced experimentally, they will take alternative routes to reach appropriate targets (Landmesser, 1980; Lance-Jones and Landmesser, 1981; Farel and Bemelmans, 1985). In the zebrafish, precise cell-specific pathfinding by the growth cones of identified pioneer motoneurons has been observed directly in living embryos (Eisen et al., 1986; Myers et al., 1986). These studies demonstrated that individual primary motoneurons extend axons directly to cell-specific locations, where they branch into characteristic areas of segmented axial muscle (Myers et al., 1986). More recent studies have shown that zebrafish primary motoneurons follow correct pathways in the absence of either activity-dependent interactions between the motoneurons and their targets (Westerfield et al., 1990) or competitive interactions among the motoneurons (Eisen et al., 1989; Pike and Eisen, 1990).

Correct pathfinding can lead a growth cone to the proper target region, but pathfinding alone cannot account for the precise shape and size of a neuron's terminal field. Once a growth cone reaches the appropriate target region, there must be mechanisms that constrain its growth and determine its choice of synaptic partners. Growth cones may be inhibited from extending into a particular region, as seems to be the case for the segmental specificity of zebrafish primary motoneurons, which do not cross the borders between muscle segments (Frost and Westerfield, 1986; Myers et al., 1986; Westerfield, 1987). On the other hand, some motor axons initially branch exuberently in target regions and later eliminate redundant projections (Purves and Lichtman, 1985). The elimination of synapses requires regressive events such as cell death or selective retraction of some of a neuron's branches. In embryonic mammals and birds, and in larval amphibians, many motoneurons die, including some whose axons have reached the target region (Oppenheim, 198 1a; Bctz, 1987). During later developmental stages, large numbers of neuromuscular synapses are eliminated (Purves and Lichtman, 1980). Regressive events also occur in invertebrate nervous systems in which they may play a role in establishing synaptic specificity (Murphey, 1986; Gao and Macagno, 1987). In most systems, regressive events appear to be regulated by activitydependent competitive interactions among neurons (Oppenheim, 1981b; Purves and Lichtman, 1985; see also Betz et al., 1990).

To examine the relative roles of directed growth and synapse elimination in the establishment of precise terminal fields, and to assess the influence of activity-dependent competitive interactions in regulating the shape and size of axonal arbors, we studied the formation of terminal fields by primary motoneurons in the zebrafish embryo. In the adult, these motoneurons 


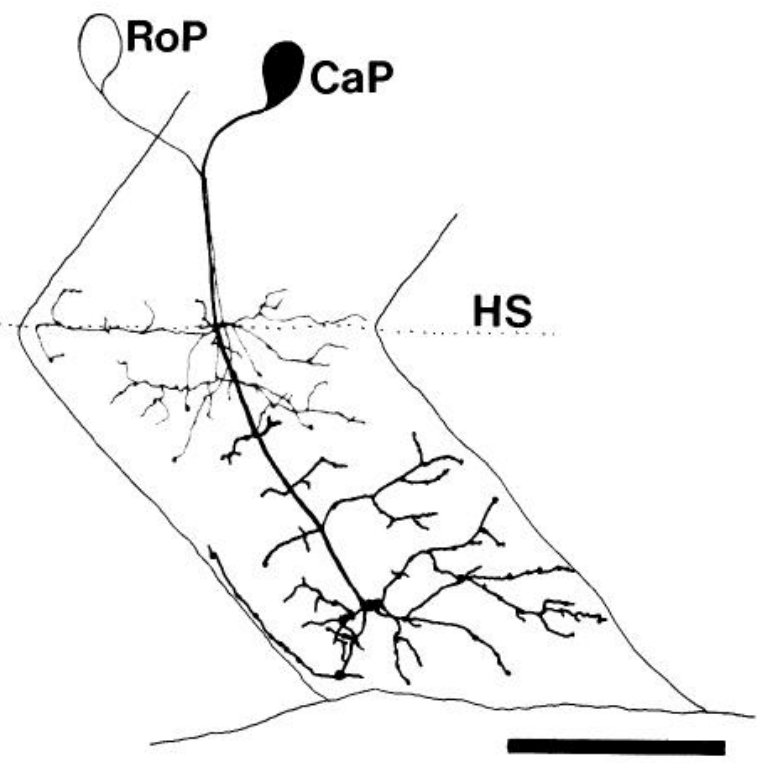

Figure 1. Terminal fields of the CaP and RoP motoneurons are mutually exclusive by third day of development. A composite drawing of a $62-\mathrm{hr} \mathrm{CaP}$ motoneuron (thick lines) and a 66-hr RoP motoneuron (thin lines) labeled with Di-I in different animals. The segment boundaries are shown as slanted lines. Rostral is to the left and dorsal to the top in this and all subsequent figures. The dorsal part of the segment is not shown. The CaP axon courses through RoP territory in the region of the horizontal septum (HS, dotted line). The CaP motoneuron is the only primary motoneuron to contact the ventral portion of the muscle. Segment 13, right for CaP and 12 left for RoP. Scale bar, $25 \mu \mathrm{m}$.

innervate adjacent, mutually exclusive muscle territories (Westerfield et al., 1986). In the embryo, primary motoneurons are the first neurons to send growth cones out of the spinal cord. We examined the formation of terminal fields by 3 of the primary motoneurons, but concentrated our efforts on the $\mathrm{CaP}$ and RoP motoneurons (Eisen et al., 1986), because these neurons innervate adjacent muscle territories and because the $\mathrm{CaP}$ growth cone must extend through putative RoP territory to reach the region it ultimately innervates (Fig. 1). The CaP and RoP growth cones follow a common pathway out of the spinal cord, and their axons are closely associated until they reach the horizontal septum, where they then proceed along divergent paths. By labeling individual $\mathrm{CaP}$ and $\mathrm{RoP}$ motoneurons with long-lasting vital fluorescent dyes, we were able to observe them directly as they established their cell-specific fields of innervation.

Our results demonstrate that a small but consistent number of branches initially project into regions that will later be innervated by other motoneurons. These branches appear to form synaptic connections with muscle fibers as evidenced by the accumulation of ACH receptors. During subsequent development, these branches are consistently retracted, suggesting that their elimination may correct errors in synaptic connectivity. By ablating individual motoneurons, we found that the elimination of these branches occurs independently of competitive interactions with other primary motoneurons converging on the same muscle fiber. The failure of axonal branches to be affected by the presence of pharmacological activity blockers and by a mutation that disrupts neuromuscular transmission further suggests that the terminal fields of these pioneer motoneurons are formed independently of neural activity.

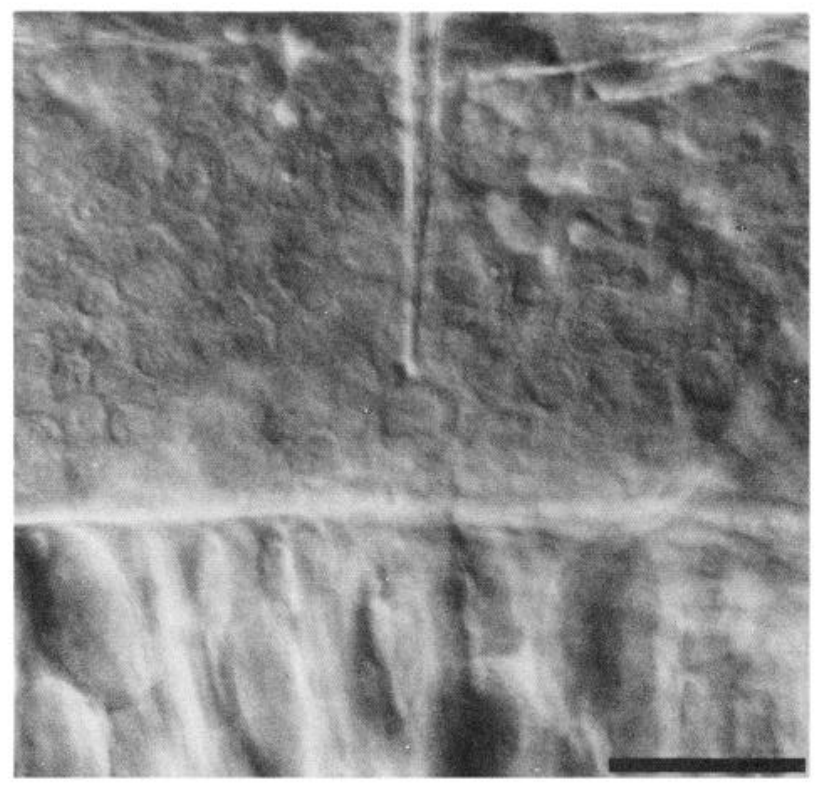

Figure 2. Individual motoneurons labeled with fluorescent dyes. A Nomarski photomicrograph illustrates the labeling method in a sagittal view of a live 19-hr zebrafish embryo with the spinal cord at the top and the notochord below. A Di-I-filled micropipette has been advanced through the spinal cord via a small opening in the dorsal skin and is prepared to eject dye directly onto the cell body of a $\mathrm{CaP}$ motoneuron. Scale bar, $20 \mu \mathrm{m}$.

\section{Materials and Methods}

Animals. Zebrafish embryos were obtained from a laboratory colony maintained on a 14-hr light, 10-hr dark cycle. Embryos were reared at $28.5^{\circ} \mathrm{C}$ and staged as previously described (Westerfield, 1989). All embryo ages are reported as hours postfertilization (hr) when raised at $28.5^{\circ} \mathrm{C}$. The nic-1(b107) mutation is a recessive, lethal mutation that was induced with gamma rays (Westerfield et al., 1990). Homozygous mutants are distinguished from wild-type embryos by their lack of spontaneous and touch-evoked movements. The muscles of nic-1 mutants respond to direct electrical stimulation but not to application of cholinergic agonists. The gol-1(b1) viable recessive mutation (Streisinger et al., 1981) affects pigmentation of the zebrafish; mutant embryos remain transparent for a much longer developmental period than wild types.

Labeling motoneurons. Individual motoneurons were identified with differential interference contrast (DIC) microscopy in the spinal cords of 17-30-hr embryos. The tips of blunt (0.5-5- $\mu \mathrm{m}$ tip diameter) micropipettes were filled with a dilute solution $(0.1-1 \%)$ of $1,1^{\prime}$-dioctadecyl3,3,3',3'-tetramethylindocarbocyanine perchlorate (Di-I) or 3,3'-dioctadecyloxacarbocyanine perchlorate (Di-O, Molecular Probes) in $N, N$-dimethylformamide. Embryos were embedded in a warm $\left(40^{\circ} \mathrm{C}\right)$ solution of $1.2 \%$ agarose in physiological saline (Westerfield et al., 1986), which allowed them to be oriented and then held fast as the agarose cooled and gelled. The gelled drop of agarose containing the embryo was kept moist in a solution of saline and $0.01 \%$ tricaine (ethyl $m$-aminobenzoate methanesulfonate, Sigma) anesthetic, which inhibited muscle contractions. A small wedge of agarose, lying over the portion of spinal cord to which access was desired, was cut and removed with a razor blade. An incision in the skin was made with a sharp micropipette in order to allow entry of the dye-filled micropipette and to reduce plugging of the tip. Embryos were then viewed with DIC optics using a $40 \times$ water-immersion objective (Zeiss) with a long working distance. Dyefilled micropipettes were advanced into the spinal cord and positioned next to the soma of the cell to be labeled (Fig. 2). Once in position, the field was illuminated with a mercury light source filtered appropriately for the specific dye in use. Pressure pulses ranging from 15 to $50 \mathrm{psi}$ for $10-100 \mathrm{msec}$ were then applied to the back of the pipette. The pressure caused a small bolus of dye, $1-5 \mu \mathrm{m}^{3}$, to be ejected from the pipette tip. The dye was taken up by the plasma membrane of the cell body and rapidly spread throughout the neuronal membrane, labeling processes 
and growth cones within minutes. After this operation, embryos were removed from the agarose and placed in physiological saline, in which they rapidly resumed normal movements. After allowing the skin to heal for several hours, the embryos were returned to normal fish water. The formation of pigment that could compromise the optics in embryos $24 \mathrm{hr}$ or older was inhibited by adding phenylthiourea $(1 \%)$ to the medium (Westerfield, 1989). Embryos treated in such a manner apparently developed normally except that they remained unpigmented for many days. To be sure that phenylthiourea did not disturb the development of primary motoneurons, we made parallel and comparable observations of labeled motoneurons in gol- 1 mutant embryos ( 3 $\mathrm{CaP}$ motoneurons and $2 \mathrm{MiP}$ motoneurons in 5 embryos).

Labeling acetylcholine receptors. Clusters of acetylcholine receptors in the axial muscles of $17-65-\mathrm{hr}$ embryos were labeled with rhodamineconjugated $\alpha$-bungarotoxin (which binds with high affinity to the $\alpha$-subunit of the acetylcholine receptor) and were subsequently viewed up to $126 \mathrm{hr}$. Embryos were soaked in a paralyzing dose of $10^{-6} \mathrm{M}$ tetramethyl-rhodamine- $\alpha$-bungarotoxin (BTX; Molecular Probes) in 15\% dimethyl sulfoxide (DMSO) and 10\% modified Hank's medium (13.7 $\mathrm{mm} \mathrm{NaCl}, 0.54 \mathrm{~mm} \mathrm{KCl}, 1.3 \mathrm{~mm} \mathrm{CaCl}_{2}, 0.1 \mathrm{mM} \mathrm{MgSO}_{4}, 0.044 \mathrm{~mm}$ $\mathrm{KH}_{2} \mathrm{PO}_{4}, 0.025 \mathrm{~mm} \mathrm{Na}_{2} \mathrm{HPO}_{4}, 0.42 \mathrm{~mm} \mathrm{NaHCO}_{3}$ ) for 30-60 min at 7$10^{\circ} \mathrm{C}$. After treatment, the embryos were transferred to cold embryo medium and were slowly warmed back to $28.5^{\circ} \mathrm{C}$. Immersion in the cold solution slowed or stopped development during the treatment, so subsequent developmental staging was 30-90 min slower than in normal, untreated embryos.

Viewing fluorescently labeled animals. For each observation, embryos were anesthetized in dilute tricaine, mounted between glass coverslips, spaced $200 \mu \mathrm{m}$ apart, and viewed with a $40 \times$ water-immersion lens with an additional magnification of $1.25-2.0 \times$. The fluorescent signal was amplified with a silicon-intensified target camera (General Electric). The video camera allowed weak signals to be detected and low light levels to be used in order to minimize photodamage and bleaching. Video images were stored on VHS tape, and some were also stored digitally for analysis with an image processor (International Imaging Systems) controlled by a VAX 11/750 computer (Digital Equipment Corp.). After each observation, embryos were transferred to a large volume of oxygenated fish water without anesthetic, except in the case of activity-blocking experiments (see below).

The lipid-soluble dyes Di-I and Di-O appeared to label motoneurons completely and to allow their development to proceed normally. In most cases, the soma, main axonal trunk, axonal varicosities, and fine side branches were discernible. Because the labeled axons were usually tipped by growth cones, it seems likely that the entire cell was labeled (see, e.g., Fig. $3 a$ ). Individual branches were observed at several successive time points. Previous experiments in zebrafish have established that fluorescent labeling and low-light-level viewing do not apparently affect the timing of development or the pattern of axonal pathfinding (Myers et al., 1986). In our studies, the rate of growth of neuronal branches prior to $25 \mathrm{hr}$, during the pathfinding phase, averaged 28.8 $\mu \mathrm{m} / \mathrm{hr}$ (range, $15.7-47.7 \mu \mathrm{m} / \mathrm{hr}$ for 5 axons in $5 \mathrm{fish}$ ). This rate is faster than that measured by Myers et al. (1986). However, their observations included the pause that the $\mathrm{CaP}$ motoneuron typically takes at the horizontal septum, whereas we measured growth ventral to the horizontal septum. This rate of growth slowed on average to $2.7 \mu \mathrm{m} / \mathrm{hr}$ (range, $1.0-7.2 \mu \mathrm{m} / \mathrm{hr}$ for 15 branches measured in 6 embryos) after 25 hr.

Ablation of motoneurons. Individually identified motoneurons were killed with a laser according to the methods of Eisen et al. (1989). The cell bodies of individual motoneurons were visualized with DIC optics (as seen in Fig. 2). RoP and MiP motoneurons were identified by the unique positions of their somata in the spinal cord at $16-18 \mathrm{hr}$, prior to axogenesis, and were killed with pulsed irradiation by focusing a laser microbeam on their nuclei. Neurons were irradiated several times to ensure complete destruction. The somata of irradiated cells acquired a granular appearance, began to swell, and completely broke apart within about $10 \mathrm{~min}$. The success of ablations was verified later with DIC optics before the CaP motoneuron was labeled.

Blocking neuromuscular activity. Three pharmacological agents were used to block neuromuscular activity: tricaine, curare, and BTX. Paralysis was indicated by lack of spontaneous movements and by failure to respond to prodding with a fine glass probe. Tricaine was initially applied at a high concentration to block the early spontaneous movements and was gradually reduced: $0.04 \%(16-22 \mathrm{hr}), 0.02 \%(22-30 \mathrm{hr})$, and $0.01 \%$ (after $30 \mathrm{hr}$ ). The tricaine solutions were replaced every 4
$10 \mathrm{hr}$. Curare ( $d$-tubocurarine chloride, Sigma), $10^{-5} \mathrm{M}$ in $10 \%$ modificd Hank's medium containing 3\% DMSO, was applied for $30 \mathrm{~min}$ and produced total paralysis. Embryos were maintained in this solution for the duration of the experiment. Lower curare concentrations $\left(10^{-6} \mathrm{M}\right)$ were used in embryos in which the tail was cut off at $17 \mathrm{hr}$ in order to gain access to internal tissues. It was necessary to cut additional tail segments off and apply fresh curare on the second day in order to maintain paralysis. These embryos developed without tail segments and had beating hearts. Their midtrunk segments were shaped normally and contained striated muscle fibers by the second day. BTX was applied at a concentration of $10^{-6} \mathrm{M}$ in $10 \%$ modified Hank's medium containing $15 \%$ DMSO as for labeling acetylcholine receptors (see above). This concentration of rhodamine-conjugated toxin labeled clusters of receptors throughout the muscles. Bungarotoxin-treated embryos lacked the early spontaneous movements of untreated cmbryos, as wcll as latcr responses to touch. However, occasional contractions of individual muscle fibers were observed, usually in the form of tremors. Toxin was reapplied to treated embryos every $12 \mathrm{hr}$ for the duration of the experiment (up to $3 \mathrm{~d}$ ).

\section{Results}

Axonal branches of primary motoneurons form in a stereotyped manner

\section{Extension of axonal branches}

Initial outgrowth. The basic patterns of growth of the 3 identified primary motoneurons, $\mathrm{RoP}, \mathrm{MiP}$, and $\mathrm{CaP}$, were very similar even though their growth cones followed cell-specific, divergent pathways into the muscle. For each cell, initial extension of the leading growth cone rapidly delimited the target territory with a relatively unbranched axon. Later, innervation of the region was consolidated by the extension of many higher-order branches throughout the muscle territory (Fig. 3). Thus, most of the arbor formed as the result of "back branching," the formation of side branches from the main axonal trunk, rather than from bifurcation of the leading growth cone. The back branches usually arose from varicosities that appeared as bright symmetrical swellings larger in diameter than the axonal branch. This process is described in detail below and illustrated by the example in Figure 3.

We concentrated our observations on the CaP motoneuron because it is the first motoneuron to extend a growth cone out of the spinal cord, and because its axon must traverse the putative territory of another motoneuron, RoP, on the way to its own targets as illustrated in Figure 1. The CaP motor growth cone extends out of the spinal cord directly ventrally (Myers et al., 1986), as shown in Figure $3 a$. Every CaP motoneuron we observed before $25 \mathrm{hr}$ ( $26 \mathrm{CaPs}$ in 26 animals) extended its principal growth cone to the ventral extent of its territory by 25 hr. In most cases, we were able to observe that the principal growth cone bifurcated just before reaching the ventral edge of the segment (Fig. 3a). Subsequent to bifurcation, one of the resulting branches formed a secondary axon, which grew caudally into the muscle while the other secondary branch extended laterally and, by $30 \mathrm{hr}$, into the region of the rostral segment border (Fig. $3 b$ ).

Second-order branch formation. Second-order motoneuronal branches sprouted directly from the main axonal trunk. The first second-order branches arose prior to $25 \mathrm{hr}$, usually sprouting from varicosities formed in the region of the nascent horizontal septum (Fig. 3a). Later branches appeared from varicosities distributed along the length of the main axonal trunk. In most cases (27 of $34 \mathrm{CaPs}$ in 34 animals), no new secondorder branches formed after $39 \mathrm{hr}$, and in no cases werc sccondorder branches seen to form on the main CaP axon after $48 \mathrm{hr}$. 

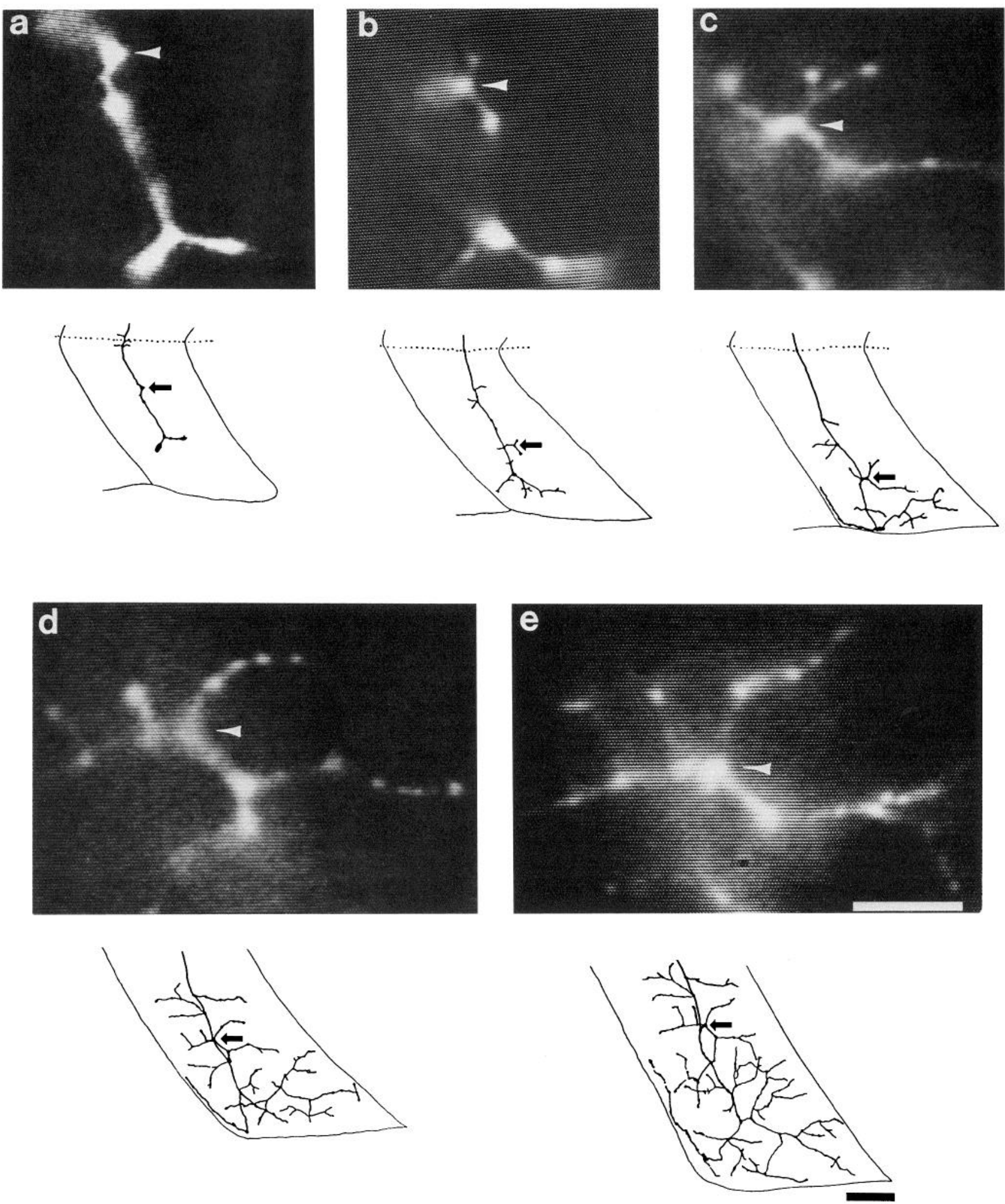

Figure 3. Side branches sprout from existing varicosities and continue to grow throughout observation period. Panels $a-e$ are taken from sequential observations of a single labeled CaP motoneuron at $24 \mathrm{hr}(a), 30 \mathrm{hr}(b), 43 \mathrm{hr}(c), 57 \mathrm{hr}(d)$, and $69 \mathrm{hr}(e)$. The photograph in the upper part of each panel shows the same field of view as it appeared at each time point, and the entire axonal arbor (drawn in thick, solid lines) is reconstructed below for reference. In this and subsequent figures, the dotted line represents the horizontal septum, and thin lines are the segment boundaries. The arrow in each drawing and the arrowhead in the corresponding photo identify the varicosity from which the side branches shown in the photo grew. The early branches $(a-c)$ grew primarily toward the caudal boundary of the segment, whereas the later branches $(d, e)$ extended toward the rostral portion of the segment. The location of the marked varicosity within the segment shifted between time points due to growth of the muscle and slight tipping of the embryo. Segment 8 , right. Scale bars: $10 \mu \mathrm{m}$, photos; $15 \mu \mathrm{m}$, drawings. 
Sccond-order CaP branches only formed in the ventral half of the segment, at or ventral to the horizontal septum. Typically ( 29 of $34 \mathrm{CaP}$ motoneurons in 34 animals), CaP motoneurons formed 1 or 2 branches at the region in which the horizontal septum will develop, then another branch several muscle-fiber diameters farther ventral (Fig. $3 b$ ). Additional secondary branches formed at regular intervals corresponding to 1 or 2 muscle-fiber diameters. Some second-order branches were tipped by growthcone-like structures, though these disappeared as the branches extended and higher-order branches formed (Fig. 3b).

Higher-order branches. We defined third-order branches as those extending from second-order branches. In turn, fourthorder branches extended from the third-order branches, and so on. Third- and higher-order branches formed later and over a more prolonged period than did second-order branches. They also frequently arose from axonal varicosities. At $24 \mathrm{hr}$, only $15 \%$ of $\mathrm{CaP}$ motor axons ( 5 of $26 \mathrm{CaP}$ motoneurons in 26 animals) had third-order branches, but by $29 \mathrm{hr}$, all the CaP motor axons had third-order branches extending from some secondary branches, though not all secondary branches had thirdorder branches. The addition of higher-order branches continued until at least $170 \mathrm{hr}$, the time of the latest observations. At these late times, the fluorescent signal from labeled branches was still strong, but the thickness and light scattering of the striated muscle fibers made further observations difficult. The extension of third-order branches was largely responsible for the innervation of the muscle territory, already delimited during the initial pathfinding stage, by filling in open areas among the second-order branches (Figs. 3, 4). Third- and higher-order branches extended from branches in all locations of the $\mathrm{CaP}$ territory (Fig. 3d,e), with the exception of the secondary branches in the region of the horizontal septum (Figs. 3a,b, 4), which never formed third-order branches.

RoP and MiP motoneurons. The RoP and MiP motoneurons followed a similar pattern of branch extension in the regions of their respective muscle territories. As previously described (Eisen et al., 1986), the MiP motoneuron initially extended a growth cone to the region in which the horizontal septum develops, then sprouted another growth cone that extended toward the dorsal half of the muscle segment. After retracting the ventral branch (see below), MiP axons followed a pattern similar to that of the CaP motoneuron, except that branches extended dorsally. The MiP growth cone bifurcated before reaching the dorsal edge of the segment ( 9 MiPs in 8 animals), then extended 1 large branch laterally and 1 rostrally into the rostral segment border. The RoP motoneuron grew to the nascent horizontal septum, then extended secondary branches laterally throughout the region of the horizontal septum (13 RoPs in 13 animals); higherorder branches then grew into the muscle regions immediately adjacent to the horizontal septum (Fig. 1).

\section{Retraction of branches}

We observed a consistent retraction of $\mathrm{CaP}$ branches from the region of the horizontal septum that ultimately becomes innervated by the RoP motoneuron. Retraction of RoP branches was never obscrved in any portion of its arbor. The majority of CaP motoneurons ( 25 of $34 \mathrm{CaP}$ motoneurons in 34 animals observed before $30 \mathrm{hr}$ ) formed 1 or more secondary branches along the main axonal trunk in the region of the horizontal septum. In every case ( 25 of $25 \mathrm{CaP}$ motoneurons), these septal branches extending from the $\mathrm{CaP}$ axon were withdrawn by $48 \mathrm{hr}$, as in the example shown in Figure 4. Third- and higher-order branch- es generally did not retract, though occasionally very fine branches near the tips of extending branches were absent in subsequent observations. We do not know however whether this indicates that some fine branches were retracted or whether we failed to observe these fine branches due to slight differences in the orientation of the animal. The time between successive observations was usually about $3 \mathrm{hr}$. Therefore, though it is possible that we missed seeing the formation and retraction of some higher-order branches, this seems unlikely because they would have to have extended and disappeared much more rapidly than the second-order septal branches that we saw consistently retract over a period of many hours.

\section{Territories of CaP and RoP motoneurons transiently overlap}

To determine whether the placement of proximal $\mathrm{CaP}$ branches produced overlap of the CaP and RoP terminal fields, we labeled both the CaP and the RoP motoneurons in the same segment, with 2 different-colored fluorescent dyes. The result of such an experiment is shown in Figure 5, where septal branches of each identified neuron could be distinguished. Near the horizontal septum, the branches of CaP and RoP motoneurons were in close proximity. We ascertained that these branches extended along the same muscle fiber using DIC optics. Although the branches of these 2 different motoneurons extended along the same muscle fiber, they were not always growing in the same location. It was thus unlikely that they were sharing developing synaptic sites. Later, as the RoP motoneuron formed additional branches in this area, the $\mathrm{CaP}$ branches on this fiber retracted while the ventral portion of the $\mathrm{CaP}$ arbor continued to expand profusely. This period of overlap between CaP and RoP branches consistently occurred from when RoP branches first extended into the septal region and in most cases persisted until about $45 \mathrm{hr}$ (Fig. 6). After this time, the CaP branches near the horizontal septum had retracted, and there was no longer significant overlap between CaP and RoP branches. By $65 \mathrm{hr}$, the adult pattern of completely segregated $\mathrm{CaP}$ and $\mathrm{RoP}$ motor fields was established.

\section{Acetylcholine receptors cluster at muscle sites contacted} by neuronal branches destined to retract

We considered the possibility that the side branches that the $\mathrm{CaP}$ motoneuron extended into inappropriate regions were tentative, nonfunctional sprouts, which might not initiate endplate differentiation. Although the CaP septal branches were often short and stubby (Fig. 4), they were sometimes as long as CaP secondary branches in other locations (Fig. 5). Short branches were distinguished from axonal varicosities by their asymmetric and elongated shape. Moreover, they typically arose from axonal varicosities and developed their own varicose swellings (Fig. 7). To provide evidence that $\mathrm{CaP}$ septal branches formed functional contacts with muscle fibers near the horizontal septum, we looked for an essential component of functional neuromuscular junctions, clusters of ACH receptors. We labeled receptors with rhodamine-conjugated $\alpha$-bungarotoxin and $\mathrm{CaP}$ motoneurons with Di-O and looked for receptor clusters associated with branches that we knew from our previous observations were destined to retract. As shown in Figure 7, receptors were clustered beneath branches that subsequently retracted $(5 \mathrm{CaP}$ motoneurons in 5 animals), and the clusters formed under varicosities (Fig. 7a) just as under side branches, located farther ventrally, which were retained. Septal branches retracted in 5 

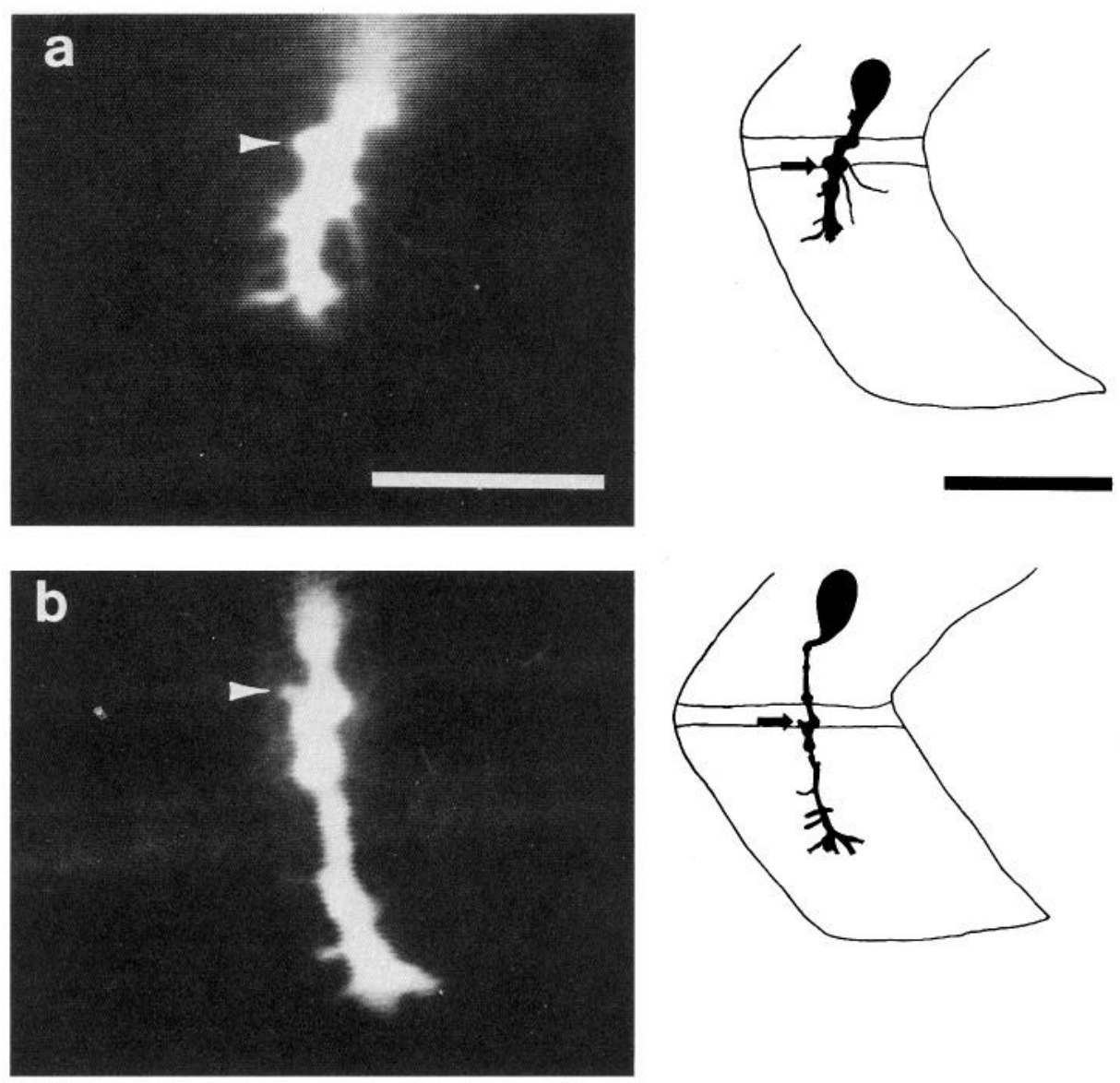

Figure 4. CaP side branches in region of horizontal septum retract over several hours. Panels $a-d$ are taken from sequential observations of a single labeled $\mathrm{CaP}$ motoneuron at $20 \mathrm{hr}(a), 22$ $\mathrm{hr}(b), 36 \mathrm{hr}(c)$, and $69 \mathrm{hr}(d)$. The photograph on the left of each panel shows the same field of view as it appeared at each time point, and the entire axonal arbor is reconstructed to the right for reference. Axonal arbors are drawn in thick, solid lines. The arrowheads in the region of the horizontal septum in each photograph and diagram identify the varicosity from which a branch extended and subsequently retracted. The branch was in contact with a single muscle fiber (outlined in drawings) near the horizontal septum. Segment 13 , right. Scale bars: $20 \mu \mathrm{m}$, photos; $30 \mu \mathrm{m}$, drawings.
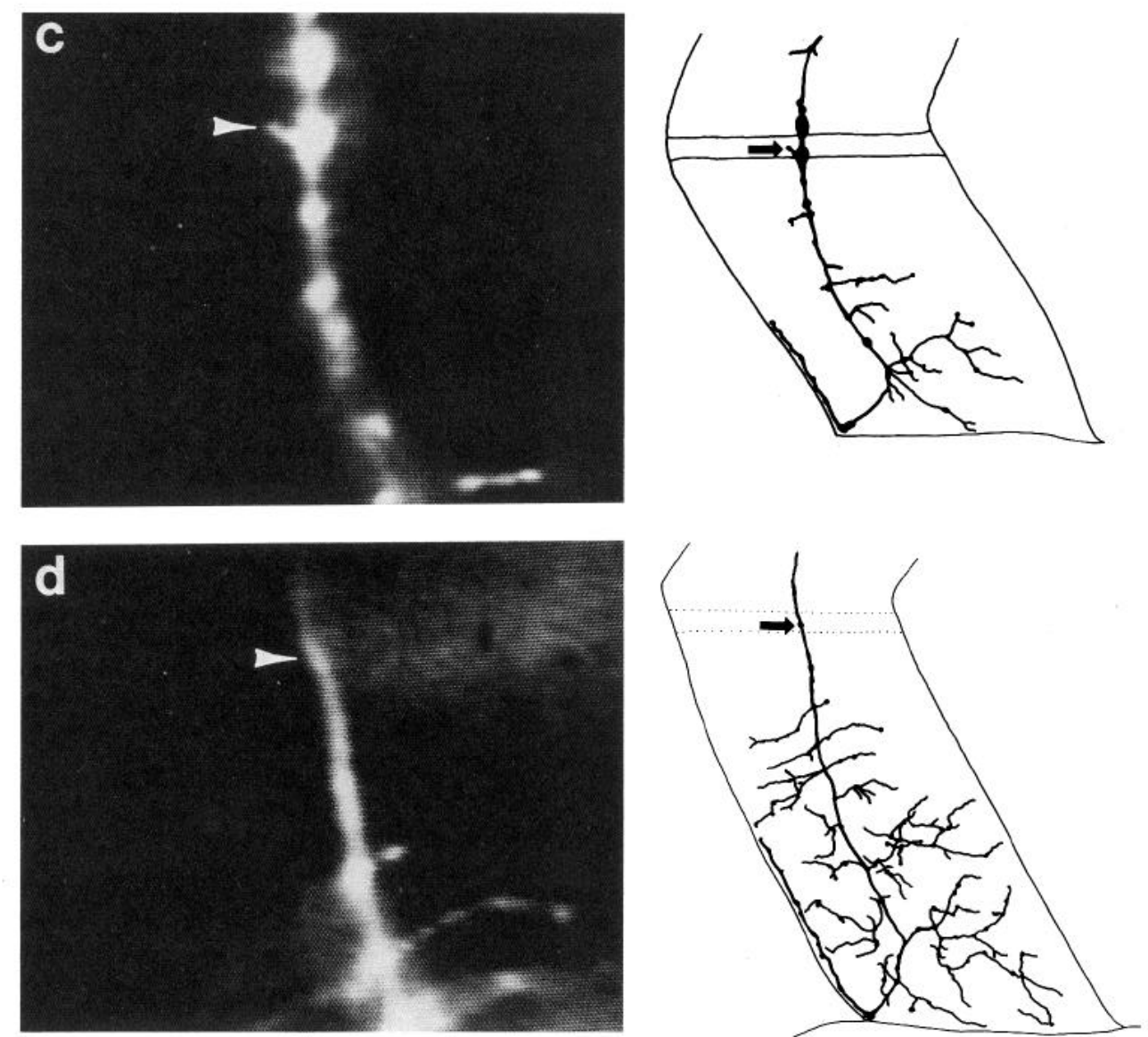

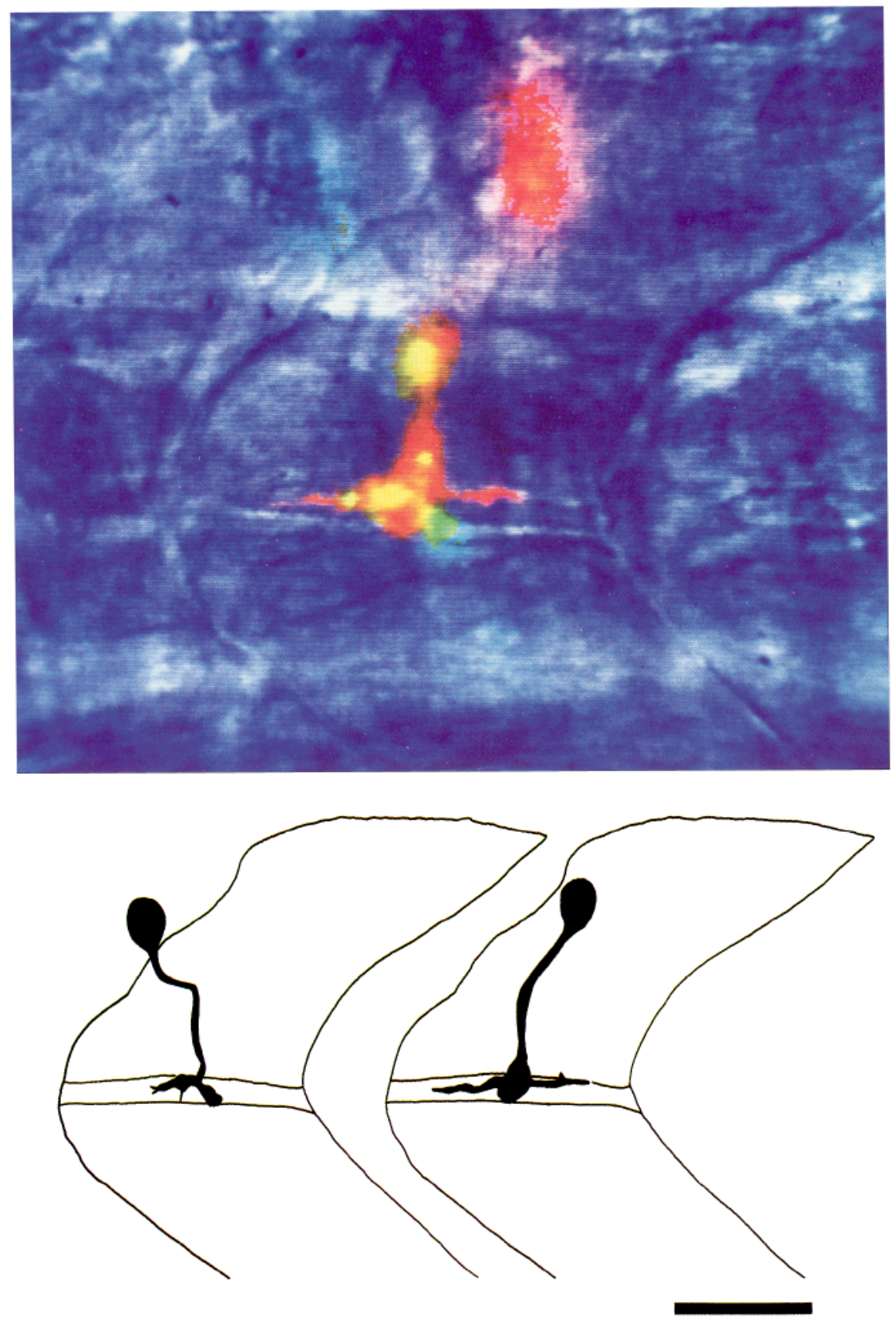

Figure 5. Early CaP and RoP axonal branches contact same muscle fiber. $T o p$, Three different images in the plane of focus of a single muscle cell at the horizontal myoseptum were superimposed to show the relative positions of the $\mathrm{CaP}$ axon (labeled with $\mathrm{Di}-\mathrm{O}$ ), the RoP axon (Di-I), and the muscle fiber (DIC optics). The CaP motoneuron had extended long branches (red) both rostrally and caudally along the muscle cell at $21 \mathrm{hr}$. At the same time, the RoP motoneuron in this segment had extended a branch rostrally along the same muscle fiber (green). The regions of overlap between the axons appear yellow. Both the $\mathrm{CaP}$ and RoP branches had prominent varicosities. Bottom, The complete arbors, reconstructed from several focal planes, are shown for the labeled RoP (left) and CaP (right) motoneurons pictured above. Segment 12 , right. Scale bar: $10 \mu \mathrm{m}$, photo; $20 \mu \mathrm{m}$, drawings. animals in which motoneurons and receptors were labeled. In 3 of these cases, receptor clusters remained for several hours after the branches retracted. In 1 case, the branches and the receptors disappeared nearly synchronously, and in the remaining case, it was impossible to determine the sequence of elimination because the addition of new clusters, presumably associated with the branches of unlabeled neurons, obscured the interpretation. In no case were receptors observed to fade or disperse prior to the retraction of neuronal branches.

After retraction of side branches and dispersal of their associated receptor clusters, receptor clusters persisted under the main trunk of the CaP axon, even along its proximal length. Although these proximal clusters condensed during subsequent development, they usually remained throughout the period of our observations. We know from previous studies (Westerfield et al., 1986) that CaP motoneurons in adult zebrafish do not innervate muscles fibers near the horizontal septum. This means that, eventually, the receptor clusters along the proximal part of the CaP axon (Fig. 7) must also be eliminated or taken over by axons of other motoneurons. In either case, these putative sites of neuromuscular transmission between the CaP motoneuron and muscle fibers near the horizontal septum are eliminated.

$\mathrm{CaP}$ branches retract normally in the absence of the other primary motoneurons

Our observations of CaP motoneurons demonstrated that the secondary branches that form near the horizontal septum always 


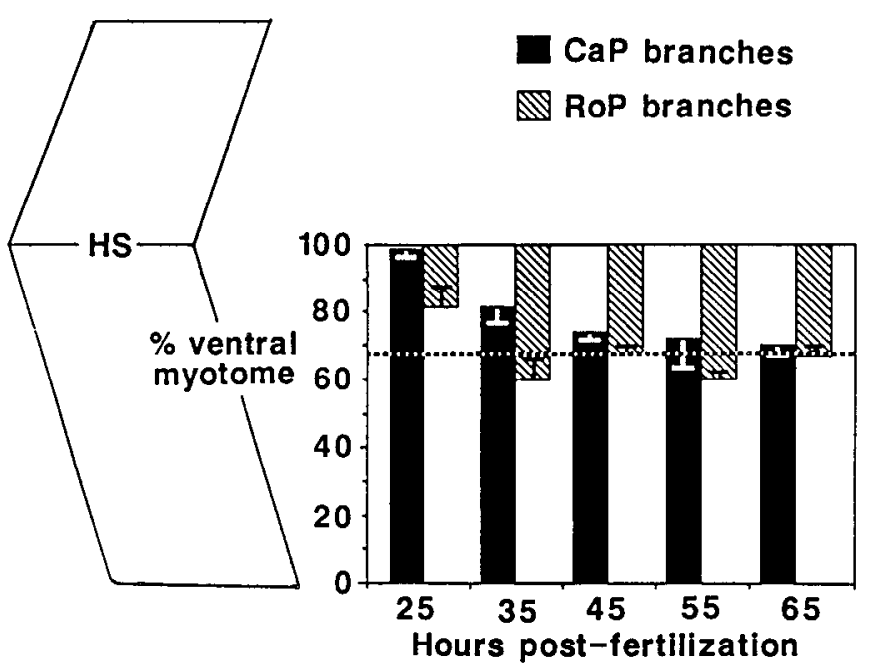

Figure 6. CaP and RoP axonal arbors transiently overlap. The locations of axonal branches of individually labeled $\mathrm{CaP}$ and RoP motoneurons were observed at different developmental times from the onset of axogenesis $(\sim 17 \mathrm{hr})$ up to $65 \mathrm{hr}$. The average locations of the most dorsal $\mathrm{CaP}$ axonal branch (solid bars) and the most ventral KoP branch (hatched bars) were calculated as a percentage of the distance between the horizontal septum $(100 \%)$ and the ventral border of the muscle segment $(0 \%)$ and were plotted as functions of developmental age, Hours postfertilization. Initially, the most dorsal $\mathrm{CaP}$ branches were located at the horizontal septum $(99 \%$ at $25 \mathrm{hr}$ ). During subsequent development, these branches retracted, so that by approximately $65 \mathrm{hr}$, the most dorsal branch was found about $1 / 3$ of the way towards the ventral edge of the muscle (70\%), similar to the location occupied by adult $\mathrm{CaP}$ branches (broken line). During the same time period, RoP branches extended farther ventrally from the region of the horizontal septum. During the first $2 \mathrm{~d}$, the most dorsal CaP branch was closer to the horizontal septum than the most ventral RoP branch and thus produced significant overlap between the $\mathrm{CaP}$ and RoP arbors. A schematic drawing of a muscle segment is shown on the left for orientation. $H S$, horizontal septum. Data are from 98 observations of $41 \mathrm{CaP}$ motoneurons in 41 animals and 39 observations of 11 RoP motoneurons in 11 animals.

retract. One explanation for retraction of these branches is that RoP or MiP axons may also be innervating muscle fibers near the horizontal septum and may compete with the CaP motoneuron for some limited resource that is required for maintenance of motor terminals. By this scenario, RoP would normally win the competition, leading to elimination of the $\mathrm{CaP}$ branches. However, we ruled out such a putative competitive interaction by ablating RoP or RoP and MiP motoneurons in individual segments by laser irradiation and observing the growth and branching pattern of the CaP motoneurons in those same segments. After $2 \mathrm{hr}$ of additional development, the CaP motoneurons in the segments where MiP and RoP had been ablated were labeled with fluorescent dye. In each case $(5$ segments in 3 animals), the CaP motoneurons developed normally. In 4 out of these 5 cases (example shown in Fig. 8), CaP branches formed near the horizontal septum and subsequently retracted over a normal time course. In the fifth case, no $\mathrm{CaP}$ branches were observed in the region of the horizontal septum.

\section{$\mathrm{CaP}$ branches retract normally in the absence of} neuromuscular activity

Another way that the retraction of $\mathrm{CaP}$ branches might be regulated is by activity-dependent interactions with the muscles or later-developing motoneurons (Myers et al., 1986). We exam- ined the potential role of activity by pharmacological block and by studying a mutant zebrafish that lacks functional $\mathrm{ACH}$ receptors [nic-1(b107); Westerfield et al., 1990].

All 3 blockers, tricaine ( 3 animals), curare ( 2 animals), and $\alpha$-BTX (8 animals), had no apparent effects on outgrowth, terminal formation, or retraction of branches. The animals were kept paralyzed from the onset of axogenesis $(16 \mathrm{hr})$ through the period of branch retraction ( $48 \mathrm{hr}$ ). An example of the outgrowth of a $\mathrm{CaP}$ motoneuron in a tricaine-treated animal is shown in Figure 9, top panels, and can be compared with the $\mathrm{CaP}$ in the untreated animal shown in Figure 3.

The outgrowth of CaP motoneurons was similarly normal in zebrafish embryos homozygous for the nic- 1 mutation, which lack functional ACH receptors (Westerfield et al., 1990). We examined the growth of labeled $\mathrm{CaP}$ motoneurons in nic- 1 embryos and, as shown by the example in Figure 9, bottom, found that $\mathrm{CaP}$ septal branches formed and retracted normally $(6 \mathrm{CaP}$ branches in 5 animals). Moreover, the shape and size of the $\mathrm{CaP}$ terminal arbor formed normally in every case (10 CaP motoneurons in 9 animals).

\section{Discussion}

Formation of terminal fields

Our extended sequential observations of individually labeled primary motoneurons are consistent with previous conclusions about the development of the zebrafish primary motor system; the growth of individual motoneurons is highly stereotyped, and pioneering motor growth cones extend directly to target regions without deviating substantially into inappropriate territory. The vast majority of side branches are placed exclusively in regions appropriate for the ultimate function of each primary motoneuron (Westerfield and Eisen, 1988).

As the primary axon initially extends, it comes into close association with muscle fibers and immediately begins forming functional connections. It then extends to the limits of its muscle territory, before sprouting a significant number of higher-order branches. A similar pattern of arborization, involving delimitation of the territory by the placement of early branches followed by consolodiation through later-forming branches, was found for chick retinal ganglion cells projecting to the developing tectum (Thanos and Bonhoeffer, 1987). During the early phase of axonal extension, when the neuronal arbor demarcates the extent of the primary motoneuron's territory, many varicosities form along the main axonal trunk and along the secondary branches. Some of these varicosities may form as the growth cone progresses, but others appear to arise after the passage of the growth cone. These varicosities give rise to higher-order branches. The $\mathrm{CaP}$ and MiP motor growth cones usually bifurcate only once in the initial delimitation of their territories. These observations suggest that growth-cone bifurcations are probably not the principal means of branch pattern formation, but rather, higher-order branches form by "backbranching" behind the growth cone, often from axonal varicosities. Branches originating behind the principal growth cone course throughout the muscle territory and consolidate the innervation of the entire target region. A similar developmental sequence has been observed for Xenopus tadpole retinal ganglion cells that form terminal arbors in the tectum primarily by "backbranching" (Harris et al., 1987). A similar process, termed "interstial budding," has been observed in the mammalian CNS (O'Leary and Terashima, 1988). 

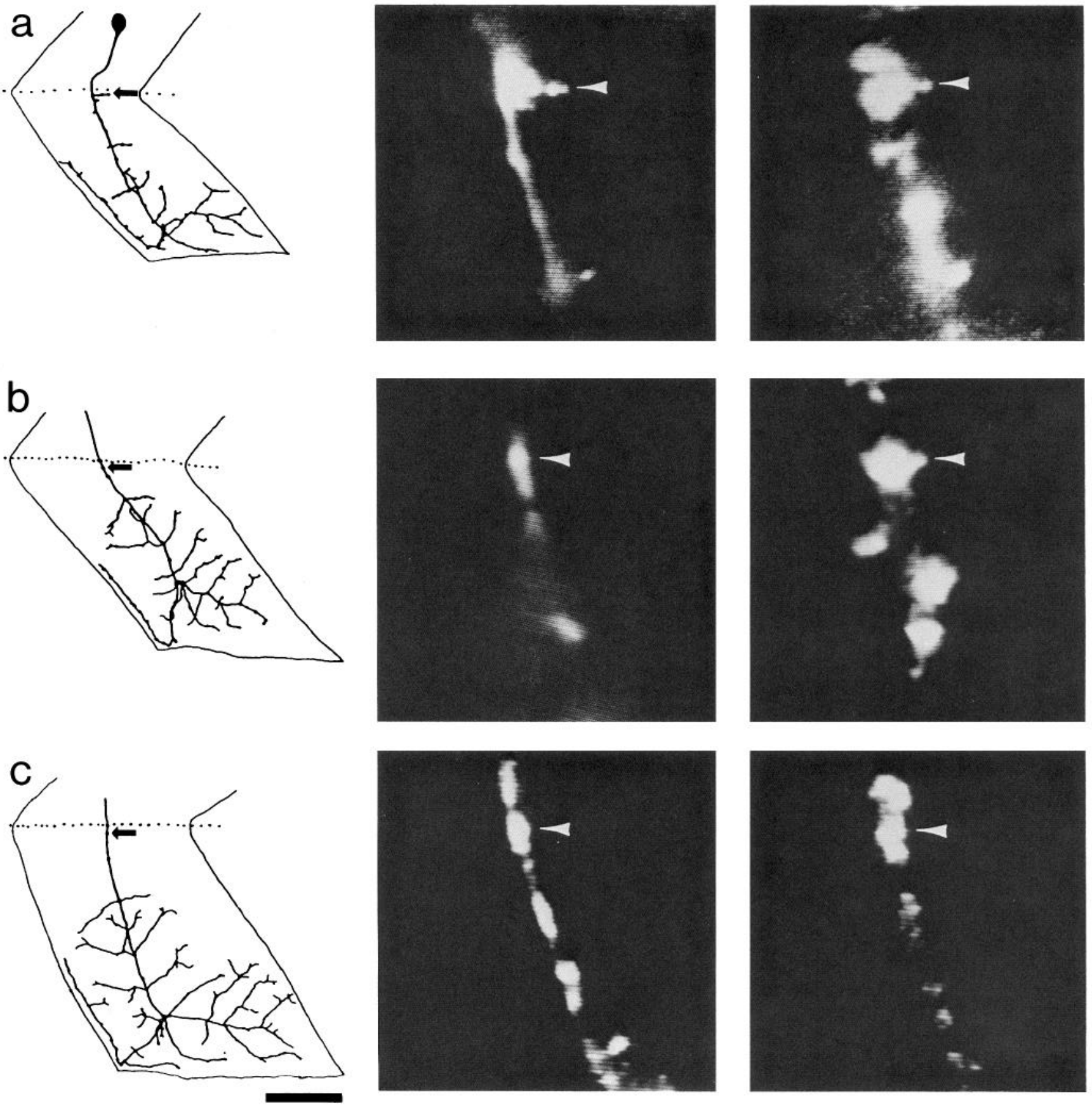

Figure 7. Clusters of ACH receptors persisted for several hours following retraction of associated axonal branches. An identified portion of a DiO-labeled $\mathrm{CaP}$ axon (middle column) and the associated clusters of $\mathrm{ACH}$ receptors labeled with a paralyzing dose of rhodamine-conjugated- $\alpha$ bungarotoxin (right column) at $43 \mathrm{hr}(a), 47 \mathrm{hr}(b)$, and $59 \mathrm{hr}(c)$. A diagram of the entire axonal arbor of this cell at each point is shown on the left. At $43 \mathrm{hr}$, there was a branch in the region of the horizontal septum with a prominent varicosity $(a$, middle $)$. The branch $(a, m i d d l e)$, including the varicosity (arrowhead), was associated with a large cluster of $\mathrm{ACH}$ receptors (arrowhead, a, right). Over the next $4 \mathrm{hr}$, the branch retracted completely (arrowhead, $b$, middle), yet the associated receptor cluster remained intact (arrowhead, $b$, right), appearing very similar to that 4 hr earlier. During the next few hours after retraction of the branch, this cluster of receptors (arrowhead, $c$, right) disappeared completely, making the larger cluster more compact. The location of the varicosity at each time point is indicated by the arrows in the drawings. Segment 10 , right. Scale bar: $30 \mu \mathrm{m}$, drawings; $8 \mu \mathrm{m}$, photos.

\section{Retraction of branches from the region of the horizontal septum}

We considered that labeled branches might retract because they are damaged or even killed due to prolonged visualization with fluorescence optics. This seems unlikely for several reasons. First, we minimized obvious damage to the axon, characterized by no growth or the development of a swollen and beaded ap- pearance, by using short exposure times and low levels of illumination. Second, branches actively growing in other parts of the neuronal arbor during the time that septal branches retracted were observed for equivalent periods with no apparent ill effect on their rates or patterns of extension. Finally, using the monoclonal antibody $\mathrm{zn}-1$, which stains primary motoneurons and other cells in fixed embryos (Myers et al., 1986), we observed septal branches on young $\mathrm{CaP}$ motoneurons but never older 

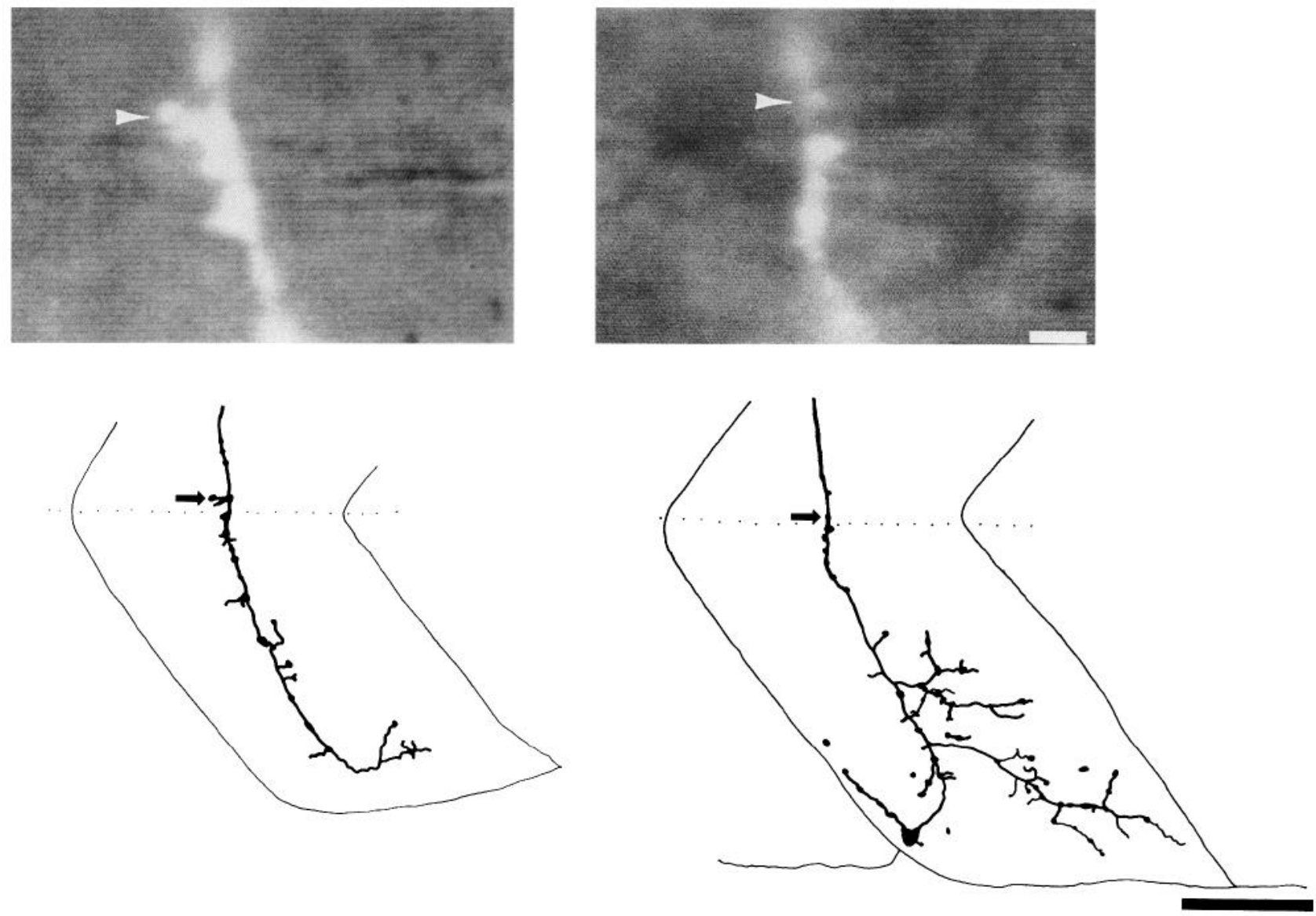

Figure 8. CaP motoneurons form normal branches in segments where MiP and RoP motoneurons have been ablated. The MiP and RoP motoneurons were laser ablated in this segment prior to axogenesis ( 16 and $\sim 16.5 \mathrm{hr}$, respectively). An individual CaP motoneuron is shown at $28 \mathrm{hr}($ left $)$ and $54 \mathrm{hr}($ right). The upper photographs show branches that were retracting by $28 \mathrm{hr}$ and had completely regressed by $54 \mathrm{hr}$ despite the elimination of putative interactions with the other primary motoneurons. The lower panels are drawings of the entire axonal arbor and illustrate that this $\mathrm{CaP}$ motoneuron established a normal branching pattern in the ventral region of the muscle. Arrowheads in the photographs and arrows in the drawings point to the varicosity at the horizontal septum. Segment 12 , left. Scale bars: $5 \mu \mathrm{m}$, photos; $20 \mu \mathrm{m}$, drawings.

CaP motoneurons (Myers et al., 1986; Westerfield et al., 1986), consistent with the observations reported here on live embryos. Thus, it seems unlikely that our observations induced retraction of the septal branches, but rather, it seems that retraction of septal branches is part of the normal developmental program of CaP motoneurons.

We considered the possibility that retraction of proximal $\mathrm{CaP}$ and MiP branches is regulated by an intrinsic mechanism that limits the number of branches or the size of the terminal field each motoneuron makes. Although we cannot specifically rule out this possibility, it seems unlikely that there is an intrinsic limit to growth because both the number of branches and the number of terminals elaborated by the primary motoneurons increase very dramatically between embryonic stages and adulthood, and even during the period of our observations, there is rapid growth of the terminal arbors within the appropriate territory while the few misplaced branches withdraw.

These observations have demonstrated that, though most primary motoneuronal branches extend into appropriate target regions, some branches of primary motoneurons extend, albeit in a highly stereotyped manner, into regions that will ultimately be innervated by a different primary motoneuron. The $\mathrm{CaP}$ motoneuron often extends branches into the region of the hor- izontal septum that the RoP motoneuron subsequently innervates. These "inappropriate" septal branches always retract. The fact that the time of retraction correlates with the ingrowth of RoP branches led us to consider the role of RoP and other neurons in affecting the retraction of $\mathrm{CaP}$ branches.

\section{Competitive interactions}

The role of competitive interactions among neurons has been established as an important mechanism for eliminating polyneuronal innervation of vertebrate skeletal muscle and in establishing quantitative matching of the presynaptic and postsynaptic fields in some, though not all, regions of the nervous system (Purves and Lichtman, 1985). We found that CaP septal branches extended and retracted normally in the absence of the RoP and MiP motoneurons and when neuromuscular activity was blocked. These results suggest that, for zebrafish primary motoneurons, unlike other vertebrate neuromuscular systems, competitive interactions may not be a factor that regulates the retraction of branches and the elimination of nascent synaptic contacts.

In our attempt to identify competitive interactions in the terminal field and synapse formation stages of $\mathrm{CaP}$ motoneuronal development, we eliminated the most likely candidates, 

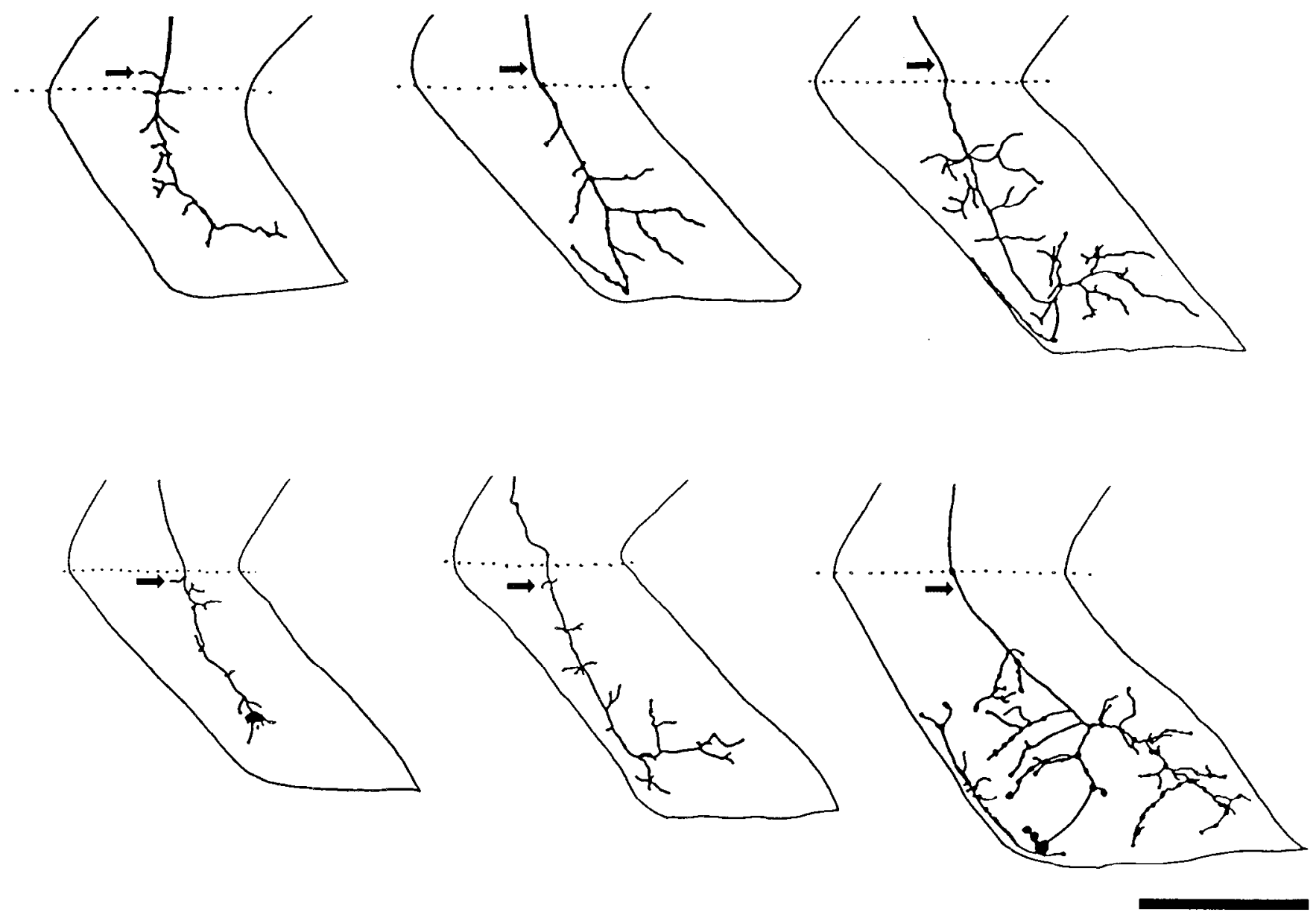

Figure 9. CaP motoneurons form normal axonal branches in paralyzed embryos. Drawings show labeled CaP motoneurons at several consecutive time points in embryos in which neuromuscular transmission was blocked with tricaine (top panels: 28,39 , and $48 \mathrm{hr}$, left to right) or by the nic1 mutation, which disrupts $\Lambda \mathrm{CH}$ receptor expression and function (bottom panels: 24,39 , and $55 \mathrm{hr}$, left to right). CaP motoneurons in treated or mutant embryos extended and retracted branches (arrows) in the region of the horizontal septum and proliferated a profuse ventral arbor as in normal embryos. Top panels: segment 12, left; bottom panels: segment 13, right. Scale bar, $40 \mu \mathrm{m}$.

the RoP and MiP motoneurons, and failed to find evidence for any interactions. This result extends previous findings (Pike and Eisen, 1990) that the primary motoneurons do not compete during the earlier pathfinding phase in development. However, there are other possible competitors. The VaP motoneuron (Eisen et al., 1990), when it is present, extends a growth cone at the same time as the other primary motoneurons. However, it is unlikely that $\mathrm{VaP}$ influenced our results because $\mathrm{VaP}$ is normally present in only $50 \%$ of segments, and we studied segments in which $\mathrm{VaP}$ was absent and saw $\mathrm{CaP}$ septal branches retract normally when RoP and MiP were ablated.

Another possibility is that secondary motoneurons induced the retraction of $\mathrm{CaP}$ septal branches because some secondary motoneurons have extended a few axons by the time that the CaP septal branches retract (Myers et al., 1986). Although our experiments do not directly rule out a role for secondary motoneurons in the retraction, it seems unlikely that this process is regulated by competitive interactions between the $\mathrm{CaP}$ and the secondary motoneurons. In adult zebrafish, primary and secondary motor axons share innervation of individual muscle fibers (Westerfield et al., 1986), and hence, there is no clear reason to expect that innervation by secondary motor axons would lead to elimination of the CaP septal branches. In fact, this tolerance of polyneuronal input may obviate or even preclude competitive mechanisms in this system, though this has not been investigated in the case of interactions among the secondary motoneurons themselves or during later stages of development of the primary motoneurons. Moreover, it seems unlikely that competition with secondary motoneurons is a regulator of CaP branches because, in neuromuscular systems (Purves and Lichtman, 1985; Betz et al., 1990; Van Essen et al., 1990), competitive interactions appear to operate through activity-dependent mechanisms, and we found that correct synaptic connections formed in the zebrafish primary motor system in the absence of activity.

\section{Role of acetylcholine receptors in branch retraction}

It is well established from observations of fixed tissue (Jacob and Lentz, 1979; Steinbach, 1981) and of muscle cells in culture (Anderson et al., 1977; Frank and Fischbach, 1979; Chow and Cohen, 1983) that ACH receptors cluster densely on muscle fibers at points of nerve contact (Peng and Poo, 1986; Steinbach and Block, 1986; Schuetze and Role, 1987). We expected that the nerve branches that ultimately innervate a given muscle fiber would be associated with receptor clusters on that fiber, but did not known whether the branches that typically retract 
could induce the clustering of $\mathrm{ACH}$ receptors, as well. For example, failure to induce clusters might be the proximal cause of branch retraction. We found, however, that all branches, including those that later retracted, were initially associated with clusters of $\mathrm{ACH}$ receptors. Further, septal branches of the $\mathrm{CaP}$ motoneuron retracted in the presence of dense clusters of receptors, and only after the branch completely retracted did these clusters disperse. Because the remaining clusters eventually dispersed, it seems unlikely that some other neuron took over the receptors and nascent synaptic sites vacated by the retracted $\mathrm{CaP}$ branch. Thus, it is unlikely that $\mathrm{CaP}$ retracts these branches because it is losing a competition for synaptic sites through the capture of receptors by branches of another motoneuron. RoP branches growing into the region of the horizontal septum do not appear to capture postsynaptic sites from the $\mathrm{CaP}$ motoneuron (Fig. 7); instead, they induce their own receptor clusters on their targets. It also seems unlikely that $\mathrm{ACH}$ receptors are necessary to mediate competitive interactions among the motoneurons because the CaP motoneuron retracted septal branches in the nic- 1 zebrafish mutant, which lacks functional $\mathrm{ACH}$ receptors and receptor clusters (Westerfield et al., 1990). Finally, because branches retract while receptor clusters are still intact, the trigger for retraction of branches in wild-type embryos cannot be the loss of $\mathrm{ACH}$ receptor clusters.

These results differ from observations in the adult mouse neuromuscular system, where the retraction of some regenerated branches follows the dispersal of ACH receptor clusters (Rich and Lichtman, 1989). The loss of receptor clusters and axonal sprouts in the mouse takes place only on fibers where branches of more than 1 neuron are competing to occupy the same preexisting muscle endplate. A variety of studies in mammals suggest that neuromuscular synapse elimination is regulated by neural activity because it can be delayed by blocking neuromuscular transmission (Van Essen, 1982; Oppenheim, 1989). Therefore, there may be a fundamental difference between primary motoneurons and later-developing (secondary) motoneurons in terms of the mechanisms that regulate the elimination of redundant synapses. Perhaps primary motoneurons depend upon specific substrate interactions (Frost and Westerfield, 1986; Westerfield, 1987) to pioneer the peripheral nerves and do not need activity-dependent mechanisms to regulate their synaptic specificity. It is also possible that activity-dependent compctitive interactions may become important later during the development of primary motoneurons.

\section{The function of septal branch extension and retraction}

$\mathrm{CaP}$ and MiP branches in the region of the horizontal septum never persist beyond the second day of development. Because they appear to induce the clustering of $\mathrm{ACH}$ receptors and may actually represent sites of transmitter release, their retraction may be necessary to eliminate synapses with inappropriate muscle fibers. If these connections were to persist, muscle fibers in the region of the horizontal septum would receive input from more than 1 primary motoneuron and selective activation of just 1 region of the muscle, as normally occurs in adults (Liu and Westerfield, 1988), might not be possible.

The highly stereotyped extension and retraction of the septal branches may indicate that important interactions arc occurring between the growth cones and something near the septum. For example, the $\mathrm{CaP}$ and $\mathrm{MiP}$ motoneurons may extend branches in the region of the horizontal septum due to specific interactions with cells in this area. Previous studies have shown that this is a location where the primary motor growth cones pause and form large axonal varicosities (Eisen et al., 1986). As discussed previously, higher-order primary motoneuronal branches tend to extend from axonal varicosities. It may be that this region is particularly attractive for growth cones and that these same properties induce and transiently stabilize branches. Similar growth-cone behavior has been observed in insects when pioneer sensory growth cones contact guidepost cells (Caudy and Bentley, 1986) or when pioneer motor growth cones encounter segment boundaries (Myers et al., 1990) or musclc pionccrs (MPs; Ball et al., 1985). The growth cones of insect pioneers slow their extension and sprout many fine side branches and filopodia when they contact guidepost cells. Some of these contacts may persist for some time, before they are eliminated, after the growth cone extends.

In zebrafish, the growth cones of the primary motoneurons may interact with a particular class of muscle cells, the MPs, at the horizontal septum (Felsenfeld and Curry, 1989). The MPs are recognized on the basis of a number of distinguishing characteristics, including precocious expression of ACHE activity (Hanneman and Westerfield, 1988), early elongation and striation (Felsenfeld et al., 1990), early expression of engrailed-like immunoreactivity (K. Hatta, personal communication), and early clustering of $\mathrm{ACH}$ receptors (D. W. C. Liu and M. Westerfield, unpublished observations). It appears, from our observations rcportcd here, that the MPs are the muscle cells near the horizontal septum upon which septal branches usually extend. Thus, contact with the MPs may induce the growth cone to pause and may consequently lead to branching and synapse formation. Once this interaction occurs and the growth cone extends beyond, the obsolete contact is eliminated. According to this view, the placement of $\mathrm{CaP}$ branches in the region of the horizontal septum is nol strictly an error in neuronal projection, but rather, reflects an important step in axonal outgrowth and the expression of a specific axonal morphology.

It appears that the few misplaced branches found in the zebrafish primary motor system may represent the by-product of the tightly regulated mechanisms that underly cell-specific pathfinding, rather than the exuberent overproduction of branches and subsequent pruning that is observed during polyneuronal innervation in other vertebrate neuromuscular systems (Van Essen, 1982). It may be that the primary motoneurons fulfill a developmental function, to pioneer the peripheral nerves (Pike et al., 1989), in addition to serving a role in behavior (Liu and Westerfield, 1988), and this developmental role is regulated by a different set of mechanisms than those that regulate the matching of populations of motoneurons to different-sized muscles by synapse elimination.

\section{References}

Anderson MJ, Cohen MW, Zorychta E (1977) Effects of innervation on the distribution of acetylcholine receptors on cultured muscle cells. J Physiol (Lond) 268:731-756.

Balice-Gordon RJ, Lichtman JW (1990) In vivo visualization of the growth of pre- and postsynaptic elements of neuromuscular junctions in the mouse. J Neurosci 10:894-908.

Ball EE, Ho RK, Goodman CS (1985) Development of neuromuscular specificity in the grasshopper embryo: guidance of motoneuron growth cones by muscle pioneers. J Neurosci 5:1808-1819.

Bentley D, Keshishian H (1982) Pathfinding by peripheral pioneer neurons in grasshoppers. Science 218:1082-1088.

Betz WJ (1987) Motoneuron death and synapse elimination in vertebrates. In: The vertebrate neuromuscular junction (Salpeter MM, ed), pp 117-162. New York: Liss. 
Betz WJ, Ribchester RR, Ridge RMAP (1990) Competitive mechanisms underlying synapse elimination in the lumbrical muscle of the rat. J Neurobiol 21:1-17.

Blair SB, Palka J (1985) Axon guidance in the wing of Drosophila. Trends Neurosci 8:284-288.

Caudy M, Bentley D (1986) Pioneer growth cone steering along a series of neuronal and non-neuronal cues of different affinities. J Neurosci 6:1781-1795.

Chow I, Cohen MW (1983) Developmental changes in the distribution of acetylcholine receptors in the myotomes of Xenopus laevis. J Physiol (Lond) 339:553-571.

Eisen JS, Myers PZ, Westerfield M (1986) Pathway selection by growth cones of identified motoneurons in live zebra fish embryos. Nature 320:269-271.

Eisen JS, Pike SH, Debu B (1989) The growth cones of identified motoneurons in embryonic zebrafish select appropriate pathways in the absence of specific cellular interactions. Neuron 2:1097-1 104.

Eisen JS, Pike SH, Romancier B (1990) An identified motoneuron with variable fates in embryonic zebrafish. J Neurosci 10:34-43.

Farel PB, Bemelmans SE (1985) Specificity of motoneuron projection patterns during development of the bullfrog tadpole (Rana catesbeiana). J Comp Neurol 238:128-134.

Felsenfeld AL, Walker C, Westerfield M, Kimmel C, Streisinger G (1990) Mutations affecting skeletal muscle myofibril structure in the zebrafish. Development 108:443-459.

Frank E, Fischbach G (1979) Early events in neuromuscular junction formation in vitro. J Cell Biol 83:143-158.

Frost D, Westerfield M (1986) Axon outgrowth of embryonic zebrafish neurons in promoted by laminin and inhibited by fibronectin. Soc Neurosci Abstr 12:1114.

Gao W-Q, Macagno ER (1987) Extension and retraction of axonal projections by some developing neurons in the leech depends upon the existence of neighboring homologues. II. The AP and AE neurons. J Neurobiol 18:295-313.

Goodman CS, Raper JA, Ho RK, Chang S (1982) Pathfinding by neuronal growth cones during grasshopper embryogenesis. Symp Soc Dev Biol 40:275-316.

Hanneman E, Westerfield M (1988) Early expression of acetylcholinesterase activity in functionally distinct neurons of the zebrafish. $J$ Comp Neurol 284:350-361.

Harris WA, Holt CE, Bonhoeffer F (1987) Retinal axons with and without their somata, growing to and arborizing in the tectum of Xenopus embryos: a time-lapse video study of single fibres in vivo. Development 101:123-133.

Jacob M, Lentz T (1979) Localization of acetylcholine receptors by means of horseradish peroxidase- $\alpha$-bungarotoxin during formation and development of the neuromuscular junction in the chick embryo. J Cell Biol 82:195-211.

Johansen J, Halpern ME, Keshishian H (1989) Axonal guidance and the development of muscle fiber-specific innervation in Drosophila embryos. J Neurosci 9:4318-4332.

Lance-Jones C, Landmesser L (1981) Pathway selection by embryonic chick motoneurons in an experimentally altered environment. Proc R Soc Lond [Biol] 214:19-52.

Landmesser L (1980) The generation of neuromuscular specificity. Annu Rev Neurosci 3:279-302.

Lichtman JW, Balice-Gordon RJ (1990) Understanding synaptic competition in theory and in practice. J Neurobiol 23:99-106.

Liu DW, Westerfield M (1988) Function of identified motoneurones and co-ordination of primary and secondary motor systems during zebra fish swimming. J Physiol (Lond) 403:73-89.

Murphey RK (1986) Competition and the dynamics of axon arbor growth in the cricket. J Comp Neurol 251:100-110.

Myers CM, Whitington PM, Ball EE (1990) Embryonic development of the innervation of the locust extensor tibia muscle by identified neurons: formation and elimination of inappropriate axon branches. Dev Biol 137:194-206.
Myers PZ, Eisen JS, Westerfield M (1986) Development and axonal outgrowth of identified motoneurons in the zebrafish. J Neurosci 6: 2278-2289.

O'Lcary DDM, Tcrashima T (1988) Cortical axons branch to multiple subcortical targets by interstitial axon budding: implications for target recognition and "waiting periods." Neuron 1:901-910.

Oppenheim RW (1981a) Cell death of motoneurons in the chick embryonic spinal cord. Evidence on the role of cell death and neuromuscular function in the formation of specific connections. J Neurosci $1: 141-151$

Oppenheim RW (1981b) Neuronal cell death and some related regressive phenomena during neurogenesis: a selective historical review and progress report. In: Studies in developmental neurobiology: essays in honor of Viktor Hamburger (Cowan WM, ed), pp. 74-133. New York: Oxford UP.

Oppenheim RW (1989) The neurotrophic theory of naturally occurring motoneuron death. Trends Neurosci 12:252-255.

Pike S, Eisen JS (1990) Identified primary motoneurons in embryonic zebrafish select appropriate pathways in the absence of other primary motoneurons. J Neurosci 10:44-49.

Pike SH, Brandenburg EF, Eisen JS (1989) Extension of motoneuronal growth cones is disrupted by the absence of pre-existing axonal pathways. Soc Neurosci Abstr 15:1262.

Peng HB, Poo MM (1986) Formation and dispersal of acetylcholine receptor clusters in muscle cells. Trends Neurosci 9:125-129.

Purves D, Lichtman JW (1980) Elimination of synapses in the developing nervous system. Science 210:153-157.

Purves D, Lichtman JW (1985) Principles of neural development. Sunderland, MA: Sinauer.

Rich MM, Lichtman JW (1989) In vivo visualization of pre- and postsynaptic changes during synapse elimination in reinnervated mouse muscle. J Neurosci 9:1781-1805.

Schuetze SM, Role LW (1987) Developmental regulation of nicotinic acetylcholine receptors. Annu Rev Neurosci 10:403-457.

Steinbach JH (1981) Developmental changes in acetylcholine receptor aggregates at rat skeletal neuromuscular junctions. Dev Biol 84:267276 .

Steinbach J H, Block R (1986) The distribution of acetylcholine receptors on vertebrate skeletal muscle cells. In: Receptors in cellular recognition and developmental processes (Gorczynski RM, ed), pp 183-213. New York. Academic.

Streisinger G, Walker C, Dower N, Knauber D, Singer F (1981) Production of clones of homozygous diploid zebra fish (Brachydanio rerio). Nature 291:293-296.

Thanos S, Bonhoeffer F (1987) Axonal arborization in the developing chick retinotectal system. J Comp Neurol 261:155-164.

Van Essen DC (1982) Neuromuscular synapse elimination: structural, functional, and mechanistic aspects. In: Neuronal development (Spitzer NC, ed) pp 333-376. New York: Plenum.

Van Essen DC, Gordon H, Soha JM, Fraser SE (1990) Synaptic dynamics at the neuromuscular junction: mechanisms and models. $\mathbf{J}$ Neurobiol 21:223-249.

Westerfield M (1987) Substrate interactions affecting motor growth cone guidance during development and regeneration. J Exp Biol 132. 161-175.

Westerfield M (1989) The zebrafish book. Eugene: University of Oregon Press.

Westerfield M, Eisen JS (1988) Neuromuscular specificity: pathfinding by identified motor growth cones in a vertebrate embryo. Trends Neurosci 11:18-22.

Westerfield M, McMurray JV, Eisen JS (1986) Identified motoneurons and their innervation of axial muscles in the zebrafish. J Neurosci 6 : 2267-2277.

Westerfield M, Liu DW, Kimmel CB, Walker C (1990) Normal pathfinding by pioneer motor growth cones in mutant zebrafish lacking functional acetylcholine receptors. Neuron 4:867-874. 